\title{
REGISTRO CIVIL E OS DIREITOS \\ DA COMUNIDADE LGBT NO BRASIL
}

\section{CIVIL REGISTRY AND LGBT RIGHTS IN BRAZIL}

Resumo: Os direitos LGBTs são frutos da constante luta da comunidade LGBT ao longo do tempo para garantir a igualdade de seus direitos frente ao ordenamento jurídico nacional. À medida que tais direitos começaram a ser incorporados no âmbito nacional provocaram inúmeros impactos na área do Direito Registral. Logo, cabe a esse artigo mapear o estado da arte dos direitos civis LGBTs no que tange à área de registros civis, esclarecendo os pontos controversos e apontando os posicionamentos mais aceitos neste campo. Com isso em mente, busca-se reafirmar a necessidade da proteção desses direitos no Brasil por meio da análise de temas como o casamento, adoção e mudança de nome e gênero a partir da investigação bibliográfica, documental e jurisprudencial.

Palavras-chave: Registro Civil. Direitos LGBTs. Direitos Humanos. Casamento. Adoção. Mudança de Nome. Alteração do Sexo.

Abstract: The LGBTs Rights are a direct result of the battle of the LGBT community throughout the years to guarantee equal rights on the national Jurisdiction. As those rights began to be incorporated nationally, they caused innumerous impacts in Registry Law. Therefore, this article will explore the evolution of the protection of LGBTs Rights, clarifying the controversial points when it comes to civil registry and pointing out the

\footnotetext{
i Pós-graduanda no curso de Direito Registral e Notarial da rede de ensino LFG/Anhanguera; Especialista em Direito Constitucional pela COJURP em Parceria com a UCAM; Bacharel em Direito pela Universidade Federal de Pernambuco, Centro de Ciências Jurídicas-CCJ, Faculdade de Direito do Recife-FDR; realizou parte do Bacharelado na Sciences Po-Paris, França, no semestre de 2012.2 e na Universität Wien, Áustria, no semestre de 2014.2; Advogada regularmente inscrita na OAB/ RJ.
} 
most accepted theories on the subjects of marriage, adoption and change of name and gender according to our bibliographic, documental and jurisprudential researches.

Keywords: Civil Registry. LGBT Rights. Human Rights. Marriage. Adoption. Name Alteration. Sex Alteration.

\section{INTRODUÇÃO}

Os direitos LGBTs são um dos temas mais controversos e inexplorados na ciência jurídica. Historicamente, tais direitos se encontravam em situação semelhante aos direitos das mulheres, isto é, não eram garantidos pelo ordenamento jurídico. No entanto, os direitos LGBTs foram e continuam sendo conquistados gradualmente, através da incessante luta desta classe, o que provocou a necessidade de adaptação na esfera jurídica para inclusão e proteção desses direitos, inclusive na área de registros civis.

Nesse sentido, tais avanços quanto aos direitos LGBTs provocaram impactos diretos na área do registro civil, os quais merecem ser abordados com mais afinco neste trabalho, por serem resultado de inúmeros debates quanto à interpretação dos comandos do ordenamento jurídico nacional e constituírem importante conquista para a área de Direitos Humanos.

Dessa forma, o presente trabalho científico terá por finalidade analisar crítica e descritivamente a evolução, ao longo dos anos, da proteção dos direitos LGBTs no âmbito nacional. Serão apresentadas as questões relevantes sobre o assunto, buscando apontar os pontos controversos na relação destes direitos com o registro civil e procurando propiciar um conhecimento coerente sobre os posicionamentos atualmente mais aceitos, a partir das posições doutrinárias e jurisprudenciais.

Assim sendo, o presente artigo será dividido em três capítulos. No primeiro capítulo será explorado o tema da união estável e casamento de casais homoafetivos. O segundo capítulo tratará da possibilidade de adoção por membros da comunidade LGBT. Já o terceiro capítulo se incumbirá de discutir a mudança de nome e alteração do sexo nos registros civis.

Para alcançar o desiderato científico proposto, a metodologia adotada para realizar a pesquisa será a dedução apoiada nas técnicas de investigação bibliográfica, documental e jurisprudência. 
Por fim, o presente trabalho científico tem como objeto de estudo a relação entre os direitos LGBTs e o registro civil, sua evolução, discussões sobre a possibilidade do casamento, da união estável, da adoção, da mudança de nome e da alteração do sexo, bem como as consequências destas para o registro civil.

\section{A UNIÃO ESTÁVEL E O CASAMENTO}

A CF estabelece que somente lei federal pode dispor sobre Direito Civil (exemplos: casamento e família); contudo, não existe no Brasil legislação que reconheça a união estável entre homossexuais. Como nosso ordenamento jurídico é regido pelo princípio da legalidade, o qual estabelece que tudo aquilo que não é proibido é permitido, tal ausência de lei não é ausência de direito e não impede que duas pessoas do mesmo sexo constituam uma união estável, podendo registrar contrato de união junto ao ofício de Registro de Títulos e Documentos (conforme art. 127 da Lei de Registros Públicos).

Nesse sentido, o direito à igualdade somente se realiza com plenitude se é garantido o direito à diferença. Assim, "não reconhecer tal união estável homoafetiva importaria uma postura discriminatória em relação à orientação sexual das pessoas, o que é vedado pela Carta Magna" (LYCHOWSKI, 2011).

Com isso em mente, em 2004 a Corregedoria Geral da Justiça do Rio Grande do Sul, tendo como base o art. 127 da Lei de Registros Públicos, expediu norma determinando que tais contratos fossem registrados (PROVIMENTO No 06/04-CGJ/RS). Como a Lei de Registros Públicos é federal, ela se aplica a todo o território nacional e, assim sendo, caso um casal tenha seu registro negado pode solicitar que seu caso seja enviado para decisão pelo juiz corregedor.

Em maio de 2011, o STF equiparou a união civil homossexual à heterossexual, reconhecendo a relação homoafetiva como instituição familiar. Essa decisão tem efeito vinculante, ou seja, é de observância obrigatória pelos demais tribunais (SUPREMO TRIBUNAL FEDERAL, 2011). Já em outubro de 2011, o STJ proferiu decisão autorizando o casamento civil entre duas mulheres que viviam em união homoafetiva (SUPERIOR TRIBUNAL DE JUSTIÇA, 2011).

A partir desses precedentes, alguns oficiais de registro passaram a celebrar casamento civil de homossexuais, enquanto outros se recusavam 
por medo de serem responsabilizados, uma vez que têm responsabilidade civil pelos danos que, na prática de atos próprios da serventia, eles e seus prepostos causarem a terceiros, o que levava os casais a pleitearem judicialmente esse direito. Contudo, como esses precedentes não têm a mesma força de uma lei, tal direito dependia da discricionariedade do juiz.

Todavia, não existe um entendimento pacífico quanto à possibilidade de conversão da união estável homoafetiva em casamento. Assim sendo, existem aqueles que defendem que a decisão do STF se limitou a reconhecer ausência de vedação constitucional à união estável homoafetiva, não sendo possível inferir-se que esta poderia ser convertida em casamento, pois isto consistiria em indevida interpretação extensiva da CF. Por outro lado, existem aqueles que, fundamentando-se nos direitos da dignidade da pessoa humana, liberdade, autodeterminação, igualdade, pluralismo, intimidade, não discriminação, busca da felicidade e segurança jurídica, defendem tal conversão.

Desse modo, não há, atualmente, uma legislação permitindo o casamento gay no Brasil, sendo tal direito amparado apenas por decisões do STF favoráveis ao casamento entre pessoas do mesmo sexo. (HAIDAR, 2011).

Assim, com objetivo de reforçar tais decisões, em 2013 o CNJ proibiu, através da Resolução 175, que as autoridades competentes para registrar a união civil entre pessoas homoafetivas, se recusem a celebrá-la e ainda foi mais além, tendo obrigado a converter a união em casamento e também à realização direta de casamento civil entre pessoas do mesmo sexo.

Logo, "se algum Cartório de Registro Civil se negar a cumprir essa resolução, o casal em questão poderá informar o ocorrido ao juiz corregedor competente para que este determine o cumprimento da medida" (HAIDAR, 2011).

Dessa forma, com a conquista do direito de se casar em 2013, os homossexuais passaram a usufruir de todos os direitos e obrigações previstos em lei, como as vantagens previdenciárias, o direito à partilha de bens e o direito sucessório.

Ademais, com o objetivo de acabar com essa controvérsia, foi proposto o Projeto de Lei 612/2011, que promove a alteração do Código Civil, para reconhecer a união estável entre pessoas do mesmo sexo e para possibilitar a conversão dessa união em casamento, assim confirmando a existência de entidade familiar homoafetiva (SENADO..., 2017). 


\subsection{Adoção}

A filiação adotiva é baseada na presunção de uma realidade afetiva, isto é, em um vínculo de amor e afeto entre as partes, não em diversidade de sexo (CUNHA, 2010).

Outrossim, a adoção "é um ato jurídico solene pelo qual se estabelece um vínculo de paternidade e filiação entre o(s) adotante(s) e adotado, independentemente de qualquer relação natural ou biológica de ambos" (CUNHA, 2010), sendo assim, um meio de proporcionar melhor qualidade de vida para crianças desprovidas de família, não parecendo ser razoável negar tal oportunidade a elas exclusivamente pela orientação sexual dos pais adotantes.

Primeiramente, o conceito de família estava ligado exclusivamente ao casamento. Contudo, com o passar do tempo, houve a ruptura de diversos paradigmas, tendo inúmeros modelos familiares conquistado seus espaços na realidade atual, o que resultou na desvinculação do conceito de família do de matrimônio e sua vinculação ao conceito de afetividade.

Colocando isso em prática, segundo Venosa (2008), a Constituição Federal conceitua a família como grupo de pessoas unido por vínculo conjugal ou de parentesco, isto é, conjunto de pessoas unidas por vínculo jurídico de natureza familiar (VENOSA, 2008, p. 2), e a estabelece como base da sociedade, conferindo a ela proteção especial do Estado.

Dessa forma, a CF, a não limitar as formações familiares, admitiu, desde que estas preencham os requisitos de afetividade e estabilidade (RICCl, 2014), o reconhecimento de outros tipos de entidades familiares.

Nessa mesma linha, a legislação nacional não faz referência à orientação sexual do adotando e, por isso, não existe nenhuma base legal que nos leve a considerar inaptos, em razão de sua opção sexual, os homossexuais que queiram adotar.

Assim sendo, em um primeiro momento, os homossexuais que quisessem adotar concorriam em processo de adoção individual, fator este que atingia o interesse do adotado pois, ao não considerar o estado civil do adotante, muitas vezes, o adotado convivia em núcleo familiar homoafetivo, porém não tinha vínculo jurídico com um dos pais.

Tendo isso em vista, pode-se dizer que o surgimento da Lei $\mathrm{n}^{\circ}$ 12.010, de 2009, ao prever a possibilidade da adoção conjunta por adotantes que vivam em união estável, trouxe importantes mudanças no instituto da adoção pois "implicitamente dá permissão para a adoção por parceiros homossexuais" (DUARTE, 2009). 
Contudo, no ordenamento jurídico brasileiro não existe legislação que regulamente a adoção por casais homossexuais que estejam em união estável, o que provoca uma estagnação no direito à adoção por casais homoafetivos (DO PRINCÍPIO..., 2016).

Porém, apesar disso, existem diversas decisões, baseadas nos princípios da dignidade humana, da igualdade, da ampla proteção à família e do melhor interesse da criança e do adolescente, favoráveis à adoção conjunta por casais homoafetivos.

A decisão do STF de 5 de maio de 2011 (SUPREMO TRIBUNAL FEDERAL, 2011) equiparou a união homoafetiva à união estável, enquadrando os casais homoafetivos no art 42, § $2^{\circ}$, do Estatuto da Criança e do Adolescente, o qual permite a adoção conjunta desde que os candidatos sejam unidos pelo matrimônio ou vivam em união estável. Desse modo, não existem mais obstáculos legais para a adoção conjunta por homossexuais (CUNHA, 2010).

O princípio da dignidade humana representa o núcleo essencial dos direitos fundamentais (BARROSO, 2009, p. 251). Dessa forma, consiste em uma qualidade inerente aos seres humanos que lhes assegura uma série de direitos e deveres fundamentais que garantem as condições existenciais mínimas (SARLET, 2010, p. 70) e que devem ser respeitados pelos seus semelhantes e pelo Estado (SARLET, 2010, p. 159), sendo inconstitucional qualquer tipo de discriminação por opção sexual (SILVA JUNIOR, 2008, p. 180).

Desse modo, "a marginalização das relações homoafetivas constitui afronta aos direitos humanos por ser forma de privação do direito à vida, violando os princípios da dignidade da pessoa humana e da igualdade" (RIO GRANDE DO SUL, 2005).

Nesse sentido, a família homoafetiva: "união de duas pessoas do mesmo sexo que tenham a intenção de se unir por laços de afetividade e com intuito duradouro, bem como devendo ser protegidas e tuteladas pelo Estado, gozando de todos os direitos e deveres inerentes a esta instituição" (GRANJA; MURAKAWA, 2012) é reconhecida pela jurisprudência atual como entidade familiar.

Todavia, apesar de em 2005 ter ocorrido a primeira adoção conjunta por casal homossexual no País, essa decisão não foi transformada em lei, o que deixa o direito de adoção por homossexuais à discricionariedade do juiz. 


\subsection{Mudança de nome e alteração do sexo}

As pessoas caracterizadas como transexuais sofrem de transtorno de identidade de gênero (ARÁN, 2009), isto é, são indivíduos que vivem em desconexão psíquico-emocional com o seu sexo biológico, considerando-se do gênero oposto ao que nasceram. Para essas pessoas a felicidade está diretamente ligada ao reconhecimento de seu nome e gênero pelo Estado.

O Código Civil concretizou o princípio da dignidade da pessoa humana, estabelecendo o nome como direito inerente a todas as pessoas. Assim sendo, o nome é parte intrínseca da personalidade de um indivíduo que tem extrema relevância social. Por essa razão, o artigo 55 da Lei de Registros Públicos, objetivando impedir abusos e garantir a dignidade dos cidadãos, proíbe o registro de prenomes suscetíveis de expor ao ridículo os seus portadores.

O princípio da imutabilidade do nome objetiva proteger tal direito, contudo, os artigos 56 a 58 da Lei de Registros Públicos estabelecem as situações em que é permitida a alteração do nome civil (SUPERIOR TRIBUNAL DE JUSTIÇA, [2014]), assim, corroborando a possibilidade da alteração dos nomes de transexuais ao confirmar a inexistência de princípios absolutos.

Em 2007, foi julgado no STJ o primeiro recurso sobre alteração de registro civil de transexuais. Nesse julgamento a Terceira Turma do STJ autorizou a alteração do nome, porém estabeleceu que deveria ser averbado no registro civil do transexual que tanto a modificação do seu nome quanto a do seu sexo decorreram de decisão judicial (SUPERIOR TRIBUNAL DE JUSTIÇA, 2007). Isto, pois a omissão de tal informação incorreria em agressão ao princípio da veracidade inerente aos registros públicos.

No entanto, em decisão de outubro de 2009, estabeleceu-se que essa averbação só deve constar em caráter sigiloso e sem fazer menção aos motivos das modificações registrais no respectivo livro do Cartório de Registro Civil e não nas certidões, para que não se mantenha o estigma contra o requerente (SUPERIOR TRIBUNAL DE JUSTIÇA, 2009).

Portanto, quanto à possibilidade de alteração do prenome no registro, não há controvérsias, entendendo-se que a vedação da modificação do prenome às pessoas que sofrem de disforia de gênero - estresse, sofrimento e desconforto causados pela incongruência entre o sexo biológico e a identidade de gênero (BONIFACIO; ROSENTHAL, 2015, p.1002) - é atitude que fere diretamente o princípio da dignidade humana (CABRAL, [2015]). 
Entretanto, existem inúmeras divergências com relação à possibilidade de modificação do sexo no registro de nascimento para que concorde com a nova identidade da pessoa.

Nesse sentido, um dos posicionamentos sobre esse assunto indica que só seria possível a correção do sexo no registro quando já realizada a cirurgia de transgenitalização, pois deve-se primar pela proteção do princípio da veracidade dos documentos públicos, devendo tais documentos representarem a verdade biológica. Isto porque os defensores desse posicionamento afirmam que a vedação da mudança do sexo no registro de nascimento não provocaria situações de constrangimento, pois a maior parte dos documentos utilizados no dia a dia não mencionam o sexo do indivíduo.

Por outro lado, a segunda corrente quanto a esse assunto, protegendo o direito dos transgêneros de viver livre de discriminações, em respeito ao princípio da dignidade, defende que é desnecessária a realização da cirurgia de mudança de sexo para que se faça a retificação do sexo no registro civil, pois não se pode "condicionar o exercício do direito à personalidade à realização de mutilação física" (TARTUCE, [2016]), porque tal ato impediria a concretização dos direitos à identidade e à felicidade (CABRAL, [2015]).

Ademais, considera-se que existem transexuais que, por inúmeras razões, não têm interesse em fazer a cirurgia de mudança de sexo e que, portanto, estariam fadados a passar por situações de constrangimento na prática dos atos da vida civil, por não poderem mudar seu registro e haver dissonância evidente entre sua imagem e os dados constantes do seu assentamento civil, o que impediria a efetivação de sua cidadania (TRANSEXUAIS..., 2017).

Em 2017, a Quarta Turma do STJ (SUPERIOR TRIBUNAL DE JUSTIÇA, 2017), em um julgamento, decidiu que é permitida a alteração do sexo no registro civil do transexual mesmo que ele não tenha realizado a cirurgia de mudança de sexo, desde que este comprove judicialmente sua mudança de gênero, porque a Turma entende que "o registro civil deve retratar a identidade de gênero psicossocial da pessoa transexual, de quem não se pode exigir a cirurgia de transgenitalização para o gozo de um direito" (TEIXEIRA, 2017).

Essa decisão do STJ não tem efeito vinculante, porém servirá de referência para casos semelhantes nas demais instâncias (STJ..., 2017).

Dessa forma, independentemente de ter realizado ou não a cirurgia de mudança de sexo, como não existe no Brasil uma legislação que 
regulamente a possibilidade de alteração do nome e sexo no registro civil, o transexual que quiser fazer essas mudanças em seu assentamento civil deverá pleiteá-las judicialmente, devendo demonstrar através de provas a sua condição de transexualidade e se sujeitando à discricionariedade da decisão de cada juiz.

Por essa razão, como tentativa de suprir tal lacuna na lei, está em tramitação na Câmara dos Deputados o Projeto de Lei 5.002/2013, que pretende assegurar ao transexual, por lei, o direito de ser tratado conforme o gênero escolhido, podendo mudar seu nome e retificar o registro de sexo sem burocracia, além de inserir a cirurgia de mudança de sexo e tratamentos hormonais dentre os tratamentos oferecidos pelo SUS, dentre outros direitos (EM MATÉRIA...,2014).

Além disso, desde 2016, é permitido aos transexuais o uso de nome social (aquele pelo qual o transexual quer ser conhecido cotidianamente, por refletir sua identidade de gênero, em detrimento do seu nome oficialmente registrado) em identificações não oficiais, nos órgãos públicos, autarquias e empresas estatais federais e o reconhecimento da identidade de gênero de travestis e transexuais (RICHTER, 2017).

\section{CONCLUSÃO}

Primeiramente, com a decisão de 2011, do STF, que igualou a união homoafetiva à união estável, o casamento deixa de ser o único modo de formar família, ficando legitimados os mais diversos formatos de unidade familiar e todos merecendo o mesmo tratamento jurídico em razão do princípio da igualdade.

No segundo capítulo, concluiu-se que não existe qualquer razão plausível para impedir aos casais homoafetivos a adoção e consequente formação de uma nova unidade familiar, principalmente, quando identificado o melhor interesse do menor, pois esta proibição, segundo a jurisprudência brasileira, incorreria em discriminação, ferindo diretamente diversos princípios constitucionais.

Já no terceiro capítulo, explorou-se o tema da possibilidade de mudança de nome e sexo no assentamento civil, ficando clara a falta de lei regulamentando a situação dos transexuais e a desnecessidade de fazer cirurgia de sexo para garantir o direito de alteração do registro civil, pois tal obrigação afrontaria diretamente o princípio da dignidade humana.

Diante do exposto, essas três temáticas são controversas e não têm reconhecimento na legislação, mas têm sido objetos de discussão 
nos tribunais, o que originou diversos precedentes que vêm guiando a maneira como se deve lidar com esses casos na atualidade.

Por fim, embora o Judiciário tente suprir essas lacunas, é necessário, para conferir-Ihes maior proteção, a criação de leis que instituam esses direitos em questão porque, em prol da segurança jurídica, não se pode deixar os homossexuais dependentes da discricionariedade do juiz.

\section{REFERÊNCIAS}

ARÁN, M.; Murta, D. Do diagnóstico de transtorno de identidade de gênero, as redescrições da experiência da transexualidade: uma reflexão sobre gênero, tecnologia e saúde. Revista Saúde Coletiva, v. 19, n. 1, p. 15-41, 2009.

BARROSO, Luiz Roberto. Curso de Direito Constitucional Contemporâneo. Rio de Janeiro: Saraiva, 2009.

BONIFACIO, Herbert J.; ROSENTHA, Stephen M. Gender Variance and Dysphoria in Children and Adolescents. Pediatric Clinicsof North America, [S.I.], v. 62, n. 4, p. 1001-1016, 2015. Disponível em: <https:// www.ncbi.nlm.nih.gov/pubmed/26210629>. Acesso em: 14 nov. 2018.

CABRAL, Maria. A mudança de nome e gênero nos transexuais sem cirurgia. Jusbrasil, [S.I.], [2015?] Disponível em:<https://mariateixeiracabral. jusbrasil.com.br/artigos/234332678/a-mudanca-de-nome-e-genero-nostransexuais-sem-cirurgia>. Acesso em: 14 nov. 2018.

DO PRINCÍPIO do melhor interesse da Criança. Disponível em: <https:// www.portaleducacao.com.br/conteudo/artigos/direito/do-principio-domelhor-interesse-da-crianca/47090 >. Acesso em: 21 nov. 2018.

CUNHA, Anna Mayara Oliveira. Adoção por casais homoafetivos: do preconceito ao Princípio da Dignidade da Pessoa Humana. Âmbito Jurídico, Rio Grande, v. 13, n. 79, ago 2010. Disponível em: <http:// www.ambito-juridico.com.br/site/index.php?n_link=revista_artigos_ leitura\&artigo_id=8165>. Acesso em: 14 nov. 2018.

DUARTE, Marcos. Nova Lei Nacional de Adoção: a perda de uma chance de fazer justiça. Família e Sucessões: Euclides de Oliveira, São Paulo, 28 jul. 2009. Disponível em: <http://www.familiaesucessoes.com.br/?p=125>. Acesso em: 14 nov. 2018. 
EM MATÉRIA especial, STJ aborda direito de transexuais alterarem registro civil. Migalhas, [S.I.], 01 dez. 2014. Especial. Disponível em: <http://www. migalhas.com.br/Quentes/17,MI212095,81042-Em+materia + especial+ST J+aborda+direito+de+transexuais+alterarem>. Acesso em: 21 nov. 2018.

GRANJA, Cícero Alexandre; MURAKAWA, Paulo Takaharo. Adoção por casais homoafetivos no Brasil. Âmbito Jurídico, Rio Grande do Sul, v. 15, n. 107, dez. 2012. Disponível em: <http://www.ambitojuridico.com. $\mathrm{br} / \mathrm{site} /$ ?n_link=revista_artigos_leitura\&artigo_id=12561 > . Acesso em: 21 nov. 2018.

HAIDAR, Rodrigo. Supremo Tribunal Federal reconhece união estável homoafetiva. Consultor Jurídico, São Paulo, 5 maio 2011. Disponível em: https://www.conjur.com.br/2011-mai-05/supremo-tribunal-federalreconhece-uniao-estavel-homoafetiva. Acesso em jan 2018.

SILVA JUNIOR, Hédio. O princípio da igualdade e os direitos de igualdade na Constituição de 1988. Revista de Direito Constitucional e Internacional, São Paulo, n. 38, p. 168-191, jan,/mar. 2008.

LYCHOWSKI, Rodrigo. A decisão do STF sobre a união estável homoafetiva: breve comentário. DireitoNet, [S.I.], 17 ago. 2011. Disponível em:<https:// www.direitonet.com.br/artigos/exibir/6426/A-decisao-do-STF-sobre-auniao-estavel-homoafetiva-breve-comentario>. Acesso em: 21 nov. 2018.

RICCl, Camilla Agustini Scalatti. Adoção homoafetiva: inexistência de impedimentos legais. Direito Net, [S.I.], 12 out. 2014. Artigos. Disponível em:<https://www.direitonet.com.br/artigos/exibir/8697/Adocaohomoafetiva-inexistencia-de-impedimentos-legais>. Acesso em: 12 nov. 2018.

RICHTER, André. Entidades defendem no STF mudança de registro civil para transexuais. Agência Brasil, Brasília, DF, 20 abr. 2017. Disponível em: <http:// agenciabrasil.ebc.com.br/direitos-humanos/noticia/2017-04/entidadesdefendem-no-stf-mudanca-de-registro-civil-para>.Acesso em: 12 nov. 2018. SARLET, Ingo Wolfgang. Dignidade da Pessoa Humana e Direitos Fundamentais: na Constituição Federal de 1988. 8. ed. Porto Alegre: 
Livraria do Advogado, 2010.

\section{RIO GRANDE DO SUL. $7^{\text {a }}$ Câmara Cível. Apelação cível nº}

70.012.836.755. Relator: Desembargadora Maria Berenice Dias. Porto Alegre, 21 de dezembro de 2005. Disponível em:

<https://www.tjrs.jus.br/busca/search?q=cache:www1.tjrs.jus.br/site_php/ consulta/consulta_processo.php\%3Fnome_comarca\%3DTribunal\%2Bde\% 2BJusti\%25E7a\%26versao\%3D\%26versao_fonetica\%3D1\%26tipo\%3D1\%2 6id_comarca\%3D700\%26num_processo_mask\%3D70012836755\%26num _processo\%3D70012836755\%26codEmenta\%3D1285687++rela\%C3\%A7 \%C3\%B5es+homoafetivas+++inmeta:adj\%3D2005\&proxystylesheet=tjrs index\&client $=$ tjrs_index\&ie $=U T F-$

8\&site $=$ ementario $\&$ access $=$ p\&oe $=$ UTF -

8\&numProcesso $=70012836755 \&$ comarca $=$ Porto $\% 20$ Alegre $\&$ dtJulg $=21 /$ 12/2005\&relator $=$ Maria\%20Berenice\%20Dias\&aba=juris >. Acesso em: 21 nov. 2018.

SUPERIOR TRIBUNAL DE JUSTIÇA. O direito dos indivíduos transexuais de alterar o seu registro civil. Jusbrasil, [S.I.], [2014?]. Disponível em:<https:// stj.jusbrasil.com.br/noticias/154275355/o-direito-dos-individuostransexuais-de-alterar-o-seu-registro-civil>. Acesso em jan 2018.

Recurso Especial: 1008398 SP 2007/0273360-5, Relator: Ministra Nancy Andrighi, Data de Julgamento: 15/10/2009, T3 - Terceira Turma, Data de Publicação: DJe 18/11/2009. JusBrasil, 2009. Disponível em: $<$ https://stj.jusbrasil.com.br/jurisprudencia/5718884/recurso-especialresp-1008398-sp-2007-0273360-5>. Acesso em: 28 set. 2018.

Recurso Especial: 1183378 RS 2010/0036663-8, Relator: Ministro Luis Felipe Salomão, Data de Julgamento: 25/10/2011, T4 - Quarta Turma, Data de Publicação: DJe 01/02/2012. JusBrasil, 2011. Disponívelem: <https://stj.jusbrasil.com.br/jurisprudencia/21285514/recurso-especialresp-1183378-rs-2010-0036663-8-stj>. Acesso em: 28 set. 2018.

Recurso Especial: 1626739 RS 2016/0245586-9, Relator: Ministro Luis Felipe Salomão, Data de Julgamento: 09/05/2017, T4 - QUARTA TURMA, Data de Publicação: DJe 01/08/2017. JusBrasil, 2017. Disponível em:<https://stj.jusbrasil.com.br/jurisprudencia/484087877/recursoespecial-resp-1626739-rs-2016-0245586-9 >. Acesso em: 28 set. 2018.

SUPREMO TRIBUNAL FEDERAL. Arguição de Descumprimento de Preceito 
Fundamental: 132 RJ, Relator: Min. Ayres Britto, Data de Julgamento: 05/05/2011, Tribunal Pleno, Data de Publicação: DJe-198 DIVULG 13-102011 PUBLIC 14-10-2011 EMENT VOL-02607-01 PP-00001. JusBrasil, 2011. Disponível em: <https://stf.jusbrasil.com.br/jurisprudencia/20627227/ arguicao-de-descumprimento-de-preceito-fundamental-adpf-132-rj-stf >. Acesso em: 28 set. 2018.

Ação Direta de Inconstitucionalidade: 4277 DF, Relator: Min. Ayres Britto, Data de Julgamento: 05/05/2011, Tribunal Pleno, Data de Publicação: DJe-198 DIVULG 13-10-2011 PUBLIC 14-10-2011 EMENT VOL02607-03 PP-00341. JusBrasil, 2011. Disponível em: <https://stf.jusbrasil. com.br/jurisprudencia/20627236/acao-direta-de-inconstitucionalidadeadi-4277-df-stf >. Acesso em: 28 set. 2018.

Recurso especial: 678933 RS 2004/0098083-5, Relator: Ministro Carlos Alberto Menezes Direito, Data de Julgamento: 22/03/2007, T3 Terceira Turma, Data de Publicação: DJ 21/05/2007 p. 571RDR vol. 41 p. 311RJTJRS vol. 265 p. 37. JusBrasil, 2007. Disponível em:<https://stj. jusbrasil.com.br/jurisprudencia/8932216/recurso-especial-resp-678933rs-2004-0098083-5/inteiro-teor-14100419?ref=juris-tabs>. Acesso em: 28 set. 2018.

TRANSEXUAIS têm direito à alteração do registro civil sem realização de cirurgia. STJ, Brasília, DF, 09 maio 2017. Disponível em:<http:// www.stj.jus.br/sites/STJ/default/pt_BR/Comunica\%C3\%A7\%C3\%A3o/ noticias/Not\%C 3\%ADcias/Transexuais-t\%C3\%AAm-direito\% C 3\% A 0-altera\%C 3\% A 7\%C3\%A 3o-do-registro-civil-semrealiza\%C3\%A7\%C3\%A3o-de-cirurgia>. Acesso em: 21 nov. 2018.

TARTUCE, Flávio. STJ entende pela possibilidade de alteração de registro civil sem cirurgia de adequação de sexo. Jusbrasil, [S.I.], [2016?] Disponível em:<https://flaviotartuce.jusbrasil.com.br/noticias/456632587/stjentende-pela-possibilidade-de-alteracao-de-registro-civil-sem-cirurgiade-adequacao-de-sexo>. Acesso em: 12 nov. 2018.

TEIXEIRA, Matheus. Transexuais têm direito de mudar o gênero no registro civil, diz 4 ${ }^{a}$ Turma do STJ. Consultor Jurídico, São Paulo, 9 maio 2017. Identidade psicossocial. Disponível em: <http://www.conjur.com.br/2017mai-09/transexuais-direito-mudar-genero-registro-civil-stj>. Acesso em: 12 nov. 2018.

VENOSA, Sílvio de Salvo. Direito Civil: Direito de família. 8 ed. São Paulo: Atlas, 2008. 